\title{
El aporte del turismo comunitario al fortalecimiento de los principios de soberanía alimentaria en el Ecuador
}

\section{Community based Tourism contribution to strengthen the food sovereignty principle in Ecuador}

\author{
Enrique Cabanilla ${ }^{1}$, Cecilia Bagnulo², Matías Álamo², Edison Molina ${ }^{1}$ \\ ${ }^{1}$ Universidad Central del Ecuador. Facultad de Ciencias Agrícolas. Carrera de Turismo Ecológico. Jerónimo Leiton y Av. La Gasca s/n. Ciudadela \\ Universitaria. 170521 Quito, Ecuador \\ ${ }^{2}$ Universidad Nacional del Sur, Bahía Blanca, Buenos Aires, Argentina
}

\begin{abstract}
Resumen
El presente artículo explora la situación del estado del hambre a nivel mundial y los programas que se están desarrollando por los organismos supranacionales. Desde este enfoque global se analiza y expone los aportes del marco constitucional y legal del Ecuador, como cuerpos que apuntalan los principios de soberanía alimentaria y su sistema alimentario, con sus respectivos procesos y subprocesos. Posteriormente se presentan algunos de los resultados obtenidos dentro del programa Impulso al Turismo Comunitario (ITC), especialmente sobre cómo se enlaza el turismo comunitario con los principios de soberanía alimentaria y cómo, este proceso productivo, puede ayudar a lograr metas claves, establecidas en los planes de desarrollo del Ecuador, en lo referente a las políticas de soberanía alimentaria. El principal objetivo es medir si efectivamente el turismo comunitario es una práctica que puede contribuir a fortalecer el concepto de soberanía alimentaria en los territorios donde se podría implantar este proceso productivo.
\end{abstract}

Palabras clave: turismo comunitario, soberanía alimentaria, estado del hambre, ley de soberanía alimentaria, nutrición, agroproducción.

\begin{abstract}
This article explores the situation of the state of world hunger and the programs that are being developed at supranational organizations level. From this comprehensive approach it is analyzes and explains the contributions of the constitutional framework of Ecuador, as bodies that underpin the principles of food sovereignty and food system, with its respective processes and threads. Then are some of the results obtained under the program that was made to reinforce Community Based Tourism, especially about community tourism that is linked to the principles of food sovereignty and how this production process, can help achieve key goals set out in the Ecuador's development plans, in terms of policies for food sovereignty. The main objective is to measure whether or not the community tourism is a practice that can help to strengthen the concept of food sovereignty in the territories where they could implement this production process.
\end{abstract}

Keywords: community tourism, food sovereignty, state of hunger, food sovereignty law, nutrition, agro-production. 


\section{Introducción. El estado del hambre y los programas para erradicarla}

Para la Organización de las Naciones Unidas para la Alimentación y la Agricultura (Food and Agriculture Organization of the United Nations, FAO) la soberanía alimentaria "existe cuando todas las personas tienen en todo momento acceso físico y económico a suficientes alimentos inocuos y nutritivos que satisfagan sus necesidades alimentarias para desarrollar una vida activa y sana" (FAO, 2015: p.1). Para el 2014 se reconoció un decremento, pero aún existen 805 millones de personas crónicamente subalimentadas. América Latina ha sido una de las regiones con mayores progresos. En Ecuador, desde la aprobación de la Constitución del 2008, hay una legislación vanguardista, mediante varios postulados en la carta magna y en una ley específica de soberanía alimentaria. La Constitución menciona:

"Art. 13.- Las personas y colectividades tienen derecho al acceso seguro y permanente a alimentos sanos, suficientes y nutritivos; preferentemente producidos a nivel local y en correspondencia con sus diversas identidades y tradiciones culturales. El Estado ecuatoriano promoverá la soberanía alimentaria" (República del Ecuador, 2008: p.5 ).

Esta declaración basada en los principios mismos del modelo del Sumak Kawsay (Buen Vivir) es fundamental para demandar todo el apoyo para construir un sistema alimentario que cumpla con lo dispuesto en la Constitución. Posteriormente, esta revolucionaria y novel carta magna, propone el Capítulo Tercero que delimita las responsabilidades del Estado, con diferentes estrategias que pueden ser visibles en la Figura 1.

Este cuerpo legal es transcendental en cuanto a sus compromisos con los actores locales, con incentivos que podrían ser fiscales o subvenciones de otro tipo, que apunten a la asistencia tecnológica, a profundizar en el derecho a la tierra, colaborar en varios procesos del sistema alimentario y provocar un agenda pública enfocada a la salud por medio de una buena y sana nutrición.

\section{Materiales y métodos de investigación}

El método mixto es una alternativa coherente y alineada para obtener los mejores resultados de la presente investigación. De esta manera se desarrolla un estudio documental sobre el marco teórico del pano- rama mundial y ecuatoriano como concepto de soberanía alimentaria y, posteriormente, un análisis de los resultados obtenidos de una investigación con el método etnográfico, que privilegia la inmersión en la comunidad para su estudio, dado en 170 comunidades del Ecuador entre el 2002 y el 2013, bajo el programa de Impulso al Turismo Comunitario auspiciado por la Universidad de Especialidades Turísticas de Quito, Ecuador. Para esto se utilizó una herramienta que facilita el trabajo de campo para: elaborar diagnósticos participativos, diseñar un plan estratégico de turismo a escala local y desarrollar un plan de negocios del principal proyecto productivo (Cabanilla, 2013).

La distribución de las comunidades responde a tres niveles: un primer nivel (A) que agrupa al $80 \%$ de las comunidades en relación de proximidad a la ciudad de Quito, con distancias que no superan las 3 horas de viaje, un segundo nivel (B) con una proximidad de hasta 5 horas de viaje (12\%) y el restante, tercer nivel (C) $8 \%$ para lugares que superan este radio (Figura 2).

Se considera una muestra válida, ya que se aplicó el método etnográfico hasta obtener resultados redundantes en los diferentes aspectos estudiados. Es afín al tema, ya que un gran porcentaje de los proyectos productivos realizados por los voluntarios con la comunidad, tiene relación directa con la provisión de alimentos y bebidas al turista, tal como lo muestra la Tabla 1.

\section{Resultados y discusión. El turismo comu- nitario como mecanismo para impulsar los objetivos y metas de los sistemas ali- mentarios y de la soberanía alimentaria}

El turismo comunitario es un modelo de acción colectiva en un territorio comunitario para dejar de ser objetos pasivos de un modelo fordista del turismo y convertirse en actores activos de un modelo posfordista de desarrollo territorial. Bajo políticas estatales de auspicio podría convertirse en un elemento clave para lograr indicadores de desarrollo como por ejemplo los Objetivos del Milenio de Naciones Unidas. Uno de los fines del modelo es la generación y redistribución de los nuevos ingresos, tanto operativos como de utilidades finales de gestión, en aquellos aspectos que se hayan decidido de forma consensuada. Un aporte fundamental es la posibilidad de fortalecer la cadena local con otras actividades productivas de las comunidades, como por ejemplo la agricultura y ganadería (Cabanilla, 2015). 


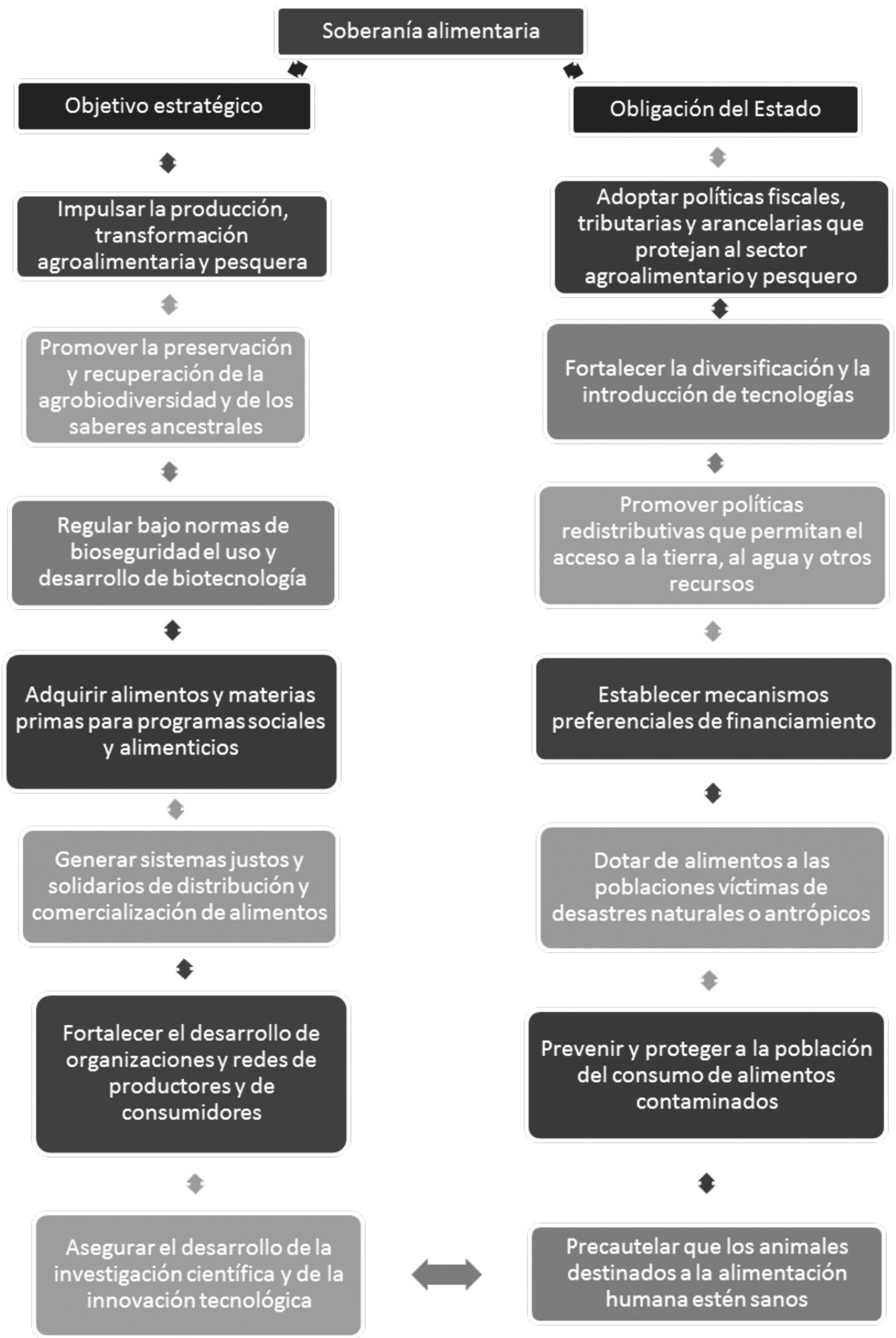

Figura 1. Deberes y estrategias del Estado ecuatoriano sobre la soberanía alimentaria. 


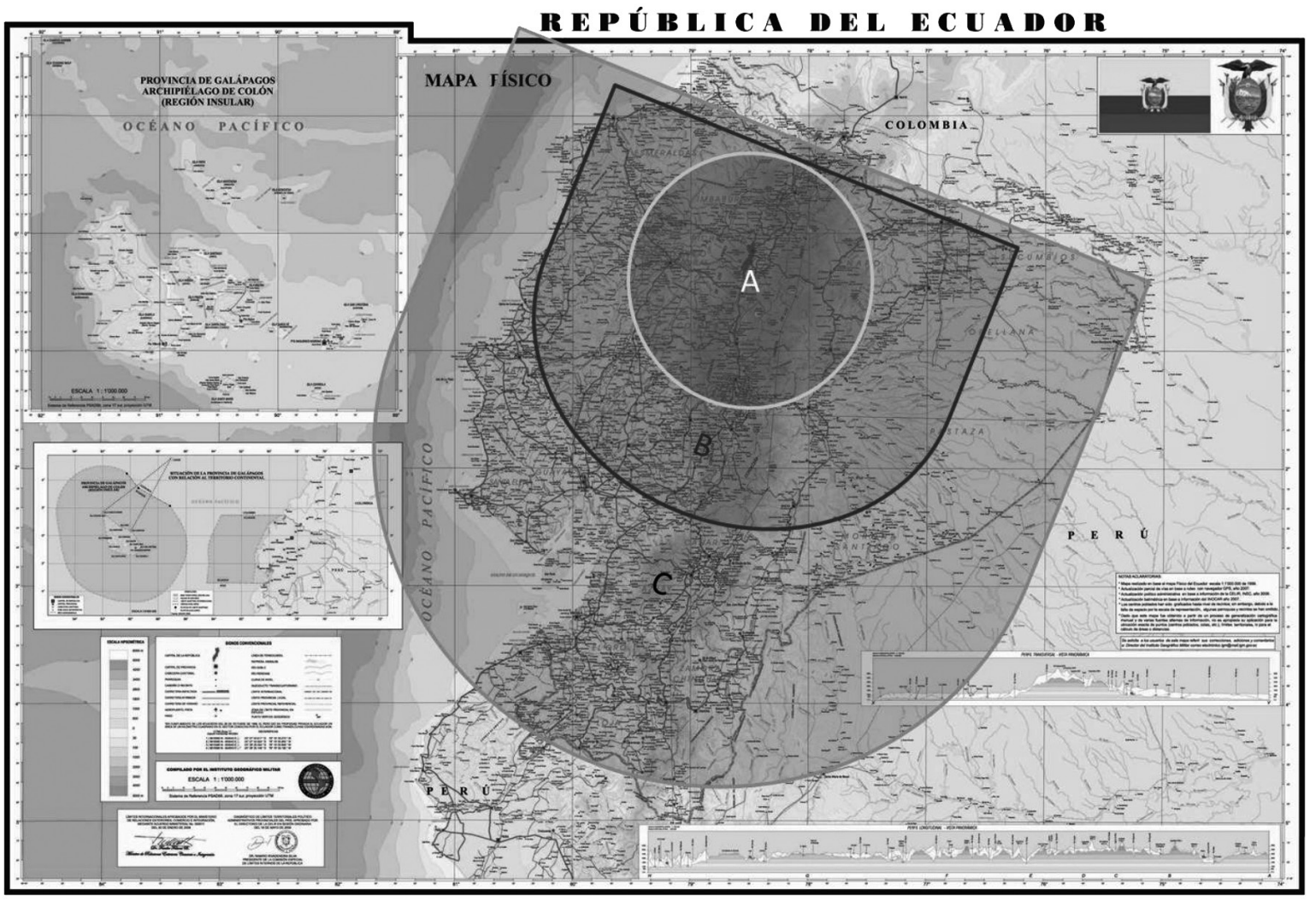

Figura 2. Distribución de los estudios trabajados con comunidades.

Fuente: Elaboración propia de los autores con datos del Instituto Geográfico Militar (IGM) del Ecuador

Tabla 1. Porcentajes de enfoques y especializaciones de los proyectos realizados bajo el programa ITC $2002-2010$.

\begin{tabular}{|c|c|c|}
\hline $\begin{array}{l}\text { Enfoque final del proyecto } \\
\text { de implantación }\end{array}$ & Porcentaje respeto al total & Subdivisión \\
\hline $\begin{array}{l}\text { Desarrollo de una empresa } \\
\text { turística comunitaria. }\end{array}$ & 68.24 & $\begin{array}{l}\text { Empresas comunitarias principalmente relacionadas con: } \\
\text { Servicios de alimentación } 30.17 \% * \\
\text { Servicios de alojamiento } 43.97 \%{ }^{*} \\
\text { Venta de artesanía } 1.72 \% \\
\text { Servicios de Información } 6.03 \% \\
\text { Operación turística } 8.62 \% * \\
\text { Servicios de recreación } 9.48 \%\end{array}$ \\
\hline $\begin{array}{l}\text { Desarrollo e implementa- } \\
\text { ción de infraestructuras para } \\
\text { el aprovechamiento de un } \\
\text { atractivo. }\end{array}$ & 25.29 & $\begin{array}{l}\text { Desarrollo basado en un atractivo: } \\
\text { Cultural } 20.93 \% \\
\text { Natural } 79.07 \%\end{array}$ \\
\hline $\begin{array}{l}\text { Programas de fortalecimien- } \\
\text { to y capacitación. }\end{array}$ & 6.47 & $\begin{array}{l}\text { Programas enfocados a la promoción } 27.27 \% \\
\text { Programas enfocados al voluntariado } 9.09 \% \\
\text { Programas de capacitación } 54.55 \% \\
\text { Programas de certificación } 9.09 \%\end{array}$ \\
\hline
\end{tabular}

4. Resultados y discusión. El turismo comunitario como mecanismo para impulsar los objetivos y metas de los sistemas alimentarios y de la soberanía alimentaria

El turismo comunitario es un modelo de acción colectiva en un territorio comunitario para dejar de ser objetos pasivos de un modelo fordista del turismo y convertirse en actores activos de un modelo posfordista de desarrollo territorial. Bajo políticas estatales de auspicio podría convertirse en un elemento clave para lograr indicadores de desarrollo, como por ejemplo, los Objetivos del Milenio de Naciones Unidas. Uno de los fines del modelo es la generación y redistribución de los 
nuevos ingresos, tanto operativos como de utilidades finales de gestión, en aquellos aspectos que se hayan decidido de forma consensuada. Un aporte fundamental es la posibilidad de fortalecer la cadena local con otras actividades productivas de las comunidades, como por ejemplo la agricultura y ganadería. (Cabanilla, 2015).
Desde este enfoque el turismo comunitario tiene varios puntos de unión con los procesos y subprocesos del sistema alimentario, bajo el cual se sostienen los objetivos planteados en la soberanía alimentaria. En la Tabla 2 se presentan los resultados y ejemplificaciones de estos enlaces.

Tabla 2: Resultados de algunos enlaces detectados en propuestas de turismo comunitario en Ecuador y el sistema alimentario, en el programa de Impulso al Turismo Comunitario (ITC)

Fuente: Elaboración propia de los autores en base a los informes del programa ITC.

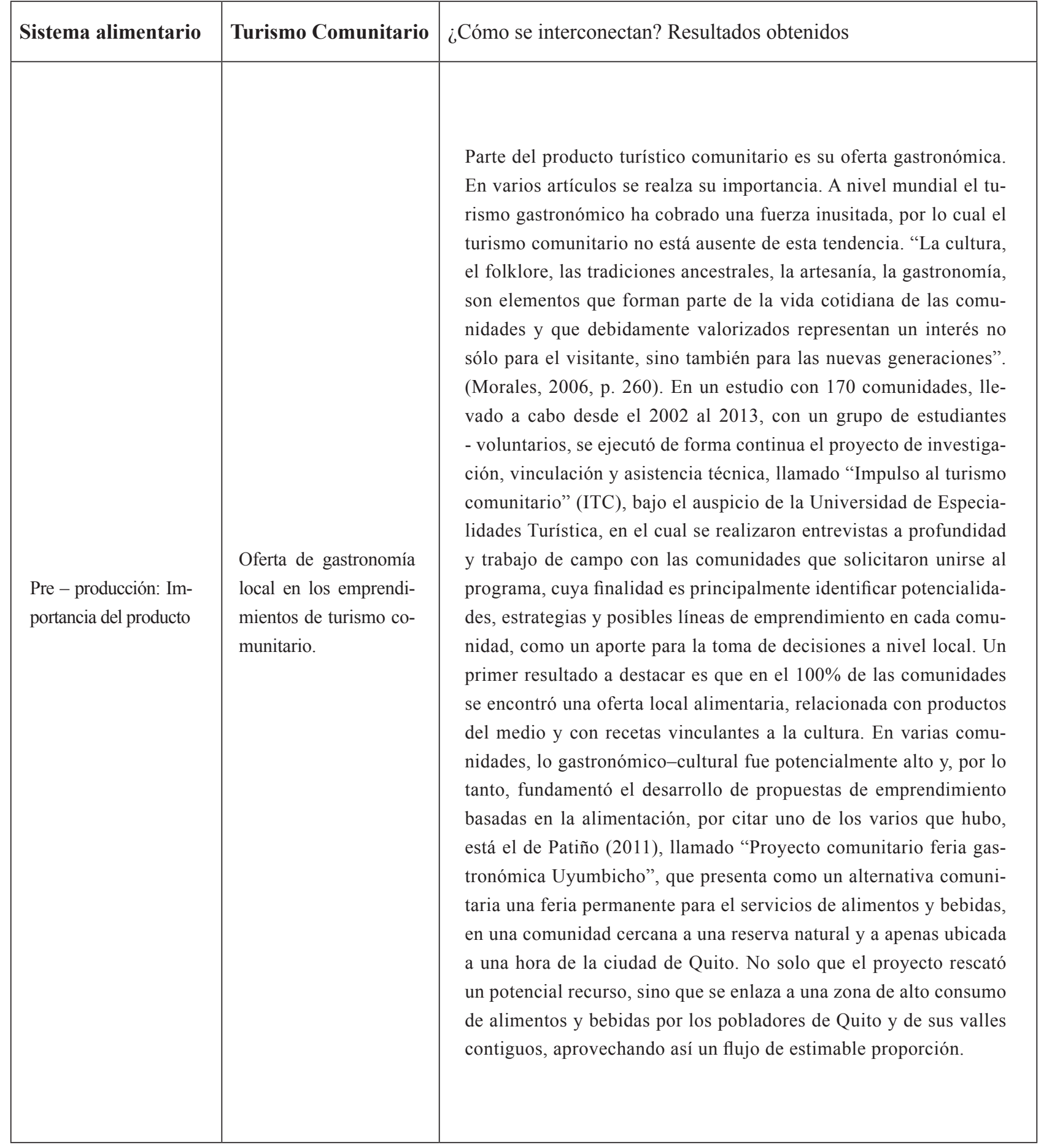




\begin{tabular}{|c|c|c|}
\hline $\begin{array}{l}\text { Pre - producción: } \\
\text { Políticas del sector } \\
\text { público }\end{array}$ & $\begin{array}{l}\text { Fortalece las cadenas de } \\
\text { valor a nivel local }\end{array}$ & $\begin{array}{l}\text { El turismo comunitario, concebido como un modelo de gestión, es } \\
\text { un eje transversal en las estrategias de desarrollo territorial. Al ser } \\
\text { una actividad vinculante al territorio, las políticas del sector público } \\
\text { tienen oportunidad de asociarlo en estrategias comunes con tipos de } \\
\text { producción agrícola, diversidad, políticas para reforzar la comercia- } \\
\text { lización local, entre otras. "Dado el visible impacto en la mejora de } \\
\text { las condiciones de vida de las comunidades implicadas, así como } \\
\text { en formas sostenibles de patrimonios y recursos naturales y cul- } \\
\text { turales, las políticas públicas deberán propender al fortalecimiento } \\
\text { de las operaciones existentes y al fomento de nuevas operaciones, } \\
\text { así como dotar de la asistencia técnica y los recursos necesarios } \\
\text { para que factores como la calidad de los servicios y productos, el } \\
\text { acceso al mercado en condiciones apropiadas, la promoción, la ar- } \\
\text { ticulación con el sector privado en términos justos -entre otros-, } \\
\text { redunden en un fortalecimiento de capacidades locales." (Ruiz \& } \\
\text { Solís, } 2007 \text {, p. } 289 \text { ) Entre los primeros estudios del programa ITC, } \\
\text { en la comunidad de San Luis de Agualongo, provincia de Imbabura } \\
\text { en Ecuador, Tamayo y Hervas (2004) presentaron el desarrollo, con- } \\
\text { sensuado con la comunidad, de una finca agroturística: "La Granja, } \\
\text { la naturaleza en tus manos", en esta propuesta el principal atractivo } \\
\text { es la agricultura como un proceso de atractividad y a la vez como } \\
\text { un proveedor de insumos alimenticios para un emprendimiento de } \\
\text { alimentación y alojamiento. En el detalle de las actividades es muy } \\
\text { evidente como lo agroproductivo es el principal motivador turístico } \\
\text { y a su vez, base de la oferta gastronómica como su principal pro- } \\
\text { veedor de insumos, reforzando el concepto de cadena local sobre lo } \\
\text { cual es muy factible desarrollar políticas que refuercen el proceso. }\end{array}$ \\
\hline $\begin{array}{l}\text { Pre - producción: } \\
\text { Instituciones relevantes }\end{array}$ & $\begin{array}{l}\text { Mundialización de un mo- } \\
\text { delo de gestión que busca } \\
\text { la sustentabilidad y armo- } \\
\text { nía de los procesos pro- } \\
\text { ductivos en los territorios. }\end{array}$ & $\begin{array}{l}\text { Hay varias instituciones que fortalecen proyectos de turismo, pero cuyo } \\
\text { principal enfoque es el tema agrícola - ganadero. Quizá uno de los } \\
\text { organismos más representativos es el Instituto Interamericano de Coo- } \\
\text { peración para la Agricultura IICA, que impulsa varios proyectos rela- } \\
\text { cionados a la implementación turística que acompaña a los procesos del } \\
\text { sistema alimentario. En un taller para tratar sus procedimientos y apoyar } \\
\text { el agroturismo (modalidad turística que ofertan varias comunidades), } \\
\text { está explícito el enfoque conceptual bajo el cual este instituto trabaja } \\
\text { en turismo. Debe haber un acuerdo entre la agricultura, el turismo, para } \\
\text { crear una ventaja competitiva para cada país, utilizando el concepto de } \\
\text { bienestar como la estrategia para la entrada en el mercado global. Con } \\
\text { base en la contratación de Fundación Solidaridad y Fundación para } \\
\text { la Paz y el Desarrollo, el programa ITC desarrolló varias intervencio- } \\
\text { nes con comunidades de la provincia de Orellana, cantón Aguarico y } \\
\text { cantón Loreto, dichos estudios formaron parte de lo que posteriormen- } \\
\text { te se convertiría en la Red Solidaria de Turismo en la Rivera del Río } \\
\text { Napo, REST }{ }^{1} \text {, y de la Red de Turismo Huataraco Suno, RETHUS } \text {, en } \\
\text { las citadas localidades. Este proceso fortalece la interacción necesaria } \\
\text { y oportuna con organizaciones no gubernamentales que pueden brin- } \\
\text { dar asistencia técnica y fortalecimiento en sus fases iniciales, al mismo } \\
\text { tiempo permite, por medio de las redes de estas ONGs, mundializar el } \\
\text { modelo de gestión y presentar esta propuesta de gestión. Es importante } \\
\text { decir que, además de la intervención en turismo, estas y otras ONGs } \\
\text { también auspician modelos de trabajo agroproductivo como el caso del } \\
\text { cacao para la zona de Loreto, o el manejo de proyectos de piscicultura } \\
\text { en la REST, construyen al mismo tiempo un sistema local que desarrolla } \\
\text { sinergias de crecimiento de varios procesos productivos. }\end{array}$ \\
\hline
\end{tabular}




\begin{tabular}{|c|c|c|}
\hline $\begin{array}{l}\text { Producción: Prácticas } \\
\text { culturales }\end{array}$ & $\begin{array}{l}\text { No pretende reemplazar } \\
\text { las prácticas culturales an- } \\
\text { cestrales, sino incorporar- } \\
\text { se como otra alternativa. }\end{array}$ & $\begin{array}{l}\text { Como una de las principales estrategias de desarrollo del turismo en } \\
\text { Ecuador, el Plan Estratégico de Desarrollo de Turismo Sostenible } \\
\text { para Ecuador - PLANDETUR, } 2020 \text { - en la estrategia } 6 \text { manifiesta } \\
\text { como acción a emprender el "Desarrollo y fortalecimiento del turis- } \\
\text { mo comunitario y patrimonio cultural para el turismo de Ecuador", } \\
\text { dentro del cual existe un proyecto específico para impulsar la certi- } \\
\text { ficación de prácticas ancestrales comunitarias para el turismo sos- } \\
\text { tenible, entre estas los temas agropecuarios. Dentro del programa } \\
\text { ITC en el año 2009, el grupo de voluntariado conformado por Llive } \\
\text { y Pacheco, trabajaron en la comunidad de San José de Saloya, en el } \\
\text { cantón San Miguel de los Bancos, a una hora y media de la ciudad } \\
\text { de Quito, la propuesta llamada "Circuito turístico de fincas comuni- } \\
\text { tarias El Naranjillado". Esta zona estuvo colonizada por el pueblos } \\
\text { yumbos entre los años } 800 \text { y } 1660 \text { d.C (Jara \& Santamarì, 2007) } \\
\text { y aporto con valiosas estructuras ceremoniales y culturales que dan } \\
\text { hoy base al Museo de Tulipe. La base de la iniciativa turística co- } \\
\text { munitaria propuesta por las voluntarias fue un circuito en el cual el } \\
\text { turista conozca y participe en las actividades cotidianas de la comu- } \\
\text { nidad, como el cultivo y cosecha de la naranjilla, la elaboración de } \\
\text { la pulpa y el naranjillado (bebida tradicional). La naranjilla es un } \\
\text { fruto originario de la zona comprendida entre Colombia, Ecuador y } \\
\text { Perú. Hay varios estudios sobre sus propiedades, pero lo más evi- } \\
\text { dente que se encontró es que la naranjilla (Solanum quitoense) está } \\
\text { presente como una práctica cultural en esta región. Las voluntarias, } \\
\text { junto con la comunidad, tomaron esta fortaleza y presentaron la idea } \\
\text { final de un circuito agroturístico. }\end{array}$ \\
\hline $\begin{array}{l}\text { Manejo en Post-Cose- } \\
\text { cha: Cosecha, empaque }\end{array}$ & $\begin{array}{l}\text { Invita a una convivencia } \\
\text { armónica entre la comu- } \\
\text { nidad receptora y sus visi- } \\
\text { tantes, conociendo y res- } \\
\text { petando sus culturas y su } \\
\text { relación con la naturaleza. }\end{array}$ & $\begin{array}{l}\text { En los productos turísticos comunitarios, en gran parte de los em- } \\
\text { prendimientos, se ofrece al turista la posibilidad de realizar acti- } \\
\text { vidades de cosecha y extracción de varios productos agrícola-ga- } \\
\text { naderos, especialmente de aquellos utilizados en las prácticas } \\
\text { alimentarias de la comunidad receptora. Los lugares son diversos, } \\
\text { a veces son chacras, terrenos pequeños, extensiones más considera- } \\
\text { bles, en ríos, lagunas e inclusive en el mar. Lo importante es que el } \\
\text { turista participa en un proceso de aprendizaje de cómo se recolectan } \\
\text { los insumos que luego van a ser parte de una preparación culinaria. } \\
\text { Esta cosecha gastronómica, es generalmente parte de las actividades } \\
\text { turísticas programadas y son desarrolladas por guías nativos que } \\
\text { involucran a los turistas a la recolección de los productos necesarios } \\
\text { para, posteriormente, elaborar la comida que les será servida por la } \\
\text { comunidad. Este involucramiento en la cosecha ha sido muy bien } \\
\text { aceptado por los turistas, como un hecho de importancia en su ex- } \\
\text { periencia de aprendizaje. En otros casos, donde la producción es de } \\
\text { un tamaño considerable, el turista es testigo y partícipe del empaque } \\
\text { y almacenamiento. Hinojosa y Barragán, en el 2006, trabajaron en } \\
\text { la comunidad de Ingapi, al noroccidente de Quito, en la propuesta } \\
\text { que se denominó "Finca modelo de agroturismo Campo Libre". Una } \\
\text { de las actividades, a gran escala, en las que las autoras, junto con } \\
\text { la comunidad, proponen la participación activa con del turista es la } \\
\text { zafra de la caña de azúcar. El turista es parte del equipo de la finca } \\
\text { que acarrea en mulas la cosecha hacia el trapiche artesanal en el } \\
\text { cual se procede con la molienda para la producción de panela, esta } \\
\text { producción es luego empaquetada para llevarla a mercados cercanos } \\
\text { o venderla a intermediarios. Hay varias experiencias como estas, en } \\
\text { las que nuevamente lo agrícola marca la pauta turística. }\end{array}$ \\
\hline
\end{tabular}




\begin{tabular}{|c|c|c|}
\hline $\begin{array}{l}\text { Mercadeo: } \\
\text { Agroprocesamiento }\end{array}$ & $\begin{array}{l}\text { El turismo comunita- } \\
\text { rio presenta una oferta } \\
\text { de atractivos vincula- } \\
\text { dos con las formas so- } \\
\text { cio-productivas de los } \\
\text { territorios, para ser mos- } \\
\text { trados a los visitantes. }\end{array}$ & $\begin{array}{l}\text { En cuanto a agroprocesos hay varios lugares especializados en pro- } \\
\text { ducción y exportación de diversos productos, entre estos cabe citar } \\
\text { la producción de quesos, mermeladas, pulpa de frutas, por citar al- } \\
\text { gunos. Esta vinculación con el turismo comunitario redunda en una } \\
\text { propuesta que torna visible el conjunto de tareas agroproductivas co- } \\
\text { munitarias y, al mismo tiempo, brinda información de la cadena de } \\
\text { valor. En los trabajos de campo realizados dentro del programa ITC, } \\
\text { Morales y Proaño (2006), realizaron el proyecto "Implementación } \\
\text { procesos mejoramiento Hostería el Refugio" en Salinas de Bolívar, } \\
\text { un poblado con alta capacidad agroprocesadora, ubicado en el centro } \\
\text { de los Andes del país a } 4 \text { horas de la ciudad de Quito, donde a través } \\
\text { de un excelente proceso cooperativo producen y comercializan varios } \\
\text { productos. En la investigación de campo se observó que inclusive se } \\
\text { realiza un circuito por el poblado para que el turista pueda observar } \\
\text { los procesos productivos de las empresas comunitarias tales como: } \\
\text { quesería El Salinerito, hilandería inter-comunal Salinas, tejidos Sa- } \\
\text { linas TEXAL, secadora de hongos, planta de elaboración de embuti- } \\
\text { dos, carpintería, mecánica industrial, taller de artesanías, piscicultu- } \\
\text { ra, fábricas de: botones, mermeladas, turrones; planta procesadora de } \\
\text { chocolate y el departamento de comercialización que se encarga de la } \\
\text { promoción y venta de todos los productos de la parroquia, mostrando } \\
\text { un proceso completo relacionado con el agroprocesamiento. }\end{array}$ \\
\hline
\end{tabular}

Fuente: Elaboración propia de los autores en base a los informes del programa ITC.

En la anterior tabla se evidencia un estrecho enlace entre varios procesos y subprocesos del sistema alimentario con el turismo comunitario, hechos que impulsan una producción ligada a los procesos ancestrales. Sin embargo, a más de lo citado anteriormente, en una convivencia armónica, el turismo comunitario y la soberanía alimentaria tienen otros puntos de conexión especialmente en temas de diversificación de la producción, sanitación y nutrición.

En cuanto a la diversificación de la producción, el turismo comunitario demanda en la colectividad el desarrollo de nuevas competencias agropecuarias que le permitan satisfacer las expectativas culinarias de los visitantes e inclusive ofertar productos dentro del llamado turismo gastronómico. Para la Organización Mundial del Turismo (OMT), en su reporte mundial del turismo gastronómico, este se concibe como "un viaje experiencial a una región gastronómica, con fines recreativos o de ocio, que incluye visitas a productores primarios y secundarios de alimentos, festivales gastronómicos, ferias gastronómicas, eventos, mercados de agricultores, demostraciones de cocina, degustaciones de productos agroalimentarios de calidad o cualquier actividad turística relacionada con los alimentos. Además, este viaje experiencial está relacionado con un estilo de vida particular, que incluye la experimentación, el aprendizaje de diferentes culturas, la adquisición de conocimientos y la comprensión de las cualidades o atributos relacionados con los productos turísticos, así como con las especialidades culinarias producidas en una región (Hall \& Sharples en WTO, 2012, p. 6). En el mismo informe destaca que el abanico de consumo va desde turistas que viajan a un lugar por el tema gastronómico de forma exclusiva, hasta aquellos en los cuales el tema de la comida es un ingrediente más de un producto turístico con otras opciones. Este abanico ha motivado que las comunidades desarrollen dos procesos, el primero un rescate sobre lo ancestral y un segundo sobre nuevas opciones culinarias basadas en los productos que se obtienen en su territorio, sean estos ancestrales o no.

En el primer caso, sobre el rescate ancestral, la diversidad se evidencia ya que los platos de comida tienen un mestizaje entre lo consumido por los antepasados, con ciertos productos que han sido incorporados actualmente. Un ejemplo de esta mixtura es un plato muy tradicional para varias comunidades del Ecuador, que comprende un cuy ${ }^{3}$ asado con algunas

\footnotetext{
3 Conocido también como conejillo de indias, cobayo, cobaya, acure, curi, cuye, cuilo, cuis o cuy es una especie de roedor histricomorfo de la familia Caviidae originaria de la región andina de América del Sur.
} 
guarniciones. Allauca y Vaca (2004), trabajaron junto con la comunidad Miño San Antonio en la parroquia San Juan de Pastocalle, provincia de Cotopaxi, distante a una hora y media de Quito, en el programa

ITC, un proyecto llamado el Palacio del Cuy, cuya propuesta básica es un restaurante especializado en servir platos cuyo ingrediente principal sea este animal. La idea principal fue desarrollar un espacio en el cual el turista pueda mirar la zona de crianza del animal, otra área donde se exhibe la principal planta que lo alimenta (alfalfa) y finalmente el restaurante. En la carta que se desarrolló se observa más claramente el principio de diversidad, pues si bien el ingrediente principal es un emblema cultural- ancestral, con la comunidad se presentaron otros platos que cubran otras preferencias del grupo de turistas, tomando en cuenta que no todos estarán dispuestos para comer cuy. Por lo tanto en la carta propuesta hay platos como arroz con una presa de pollo frito y ensalada, caldo de gallina criolla, ensalada de apio, picadillo de papas, manzanas a la canela y un plato vegetariano, que aprovechan otros productos que se producen en el sector y dan diversidad para que un mismo grupo encuentre en el Palacio del Cuy un lugar donde hay algo para cada gusto.

Con otros productos que se dan en los territorios de algunas comunidades, como el caso del palmito (Bactris gasipaes), planta nativa americana, Durán y Endara (2011), en el marco del programa ITC, recopilaron la preparación del llamado ceviche de palmito en la comunidad Paraíso Escondido Bajo, ubicada al noroccidente de Quito. Este plato se ha difundido bastamente en la zona, lleva como ingredientes: palmito, tomate, naranja, limón, cebolla, aceite de soya o maíz, culantro y sal; la mayoría de estos ingredientes se producen en la misma comunidad y en sus alrededores. La innovación de este ceviche es mezclar en su preparación el proceso del conocido plato internacional, difundido especialmente en Perú y Ecuador, y reemplazar los mariscos con un producto de la zona. De este proceso se ha desarrollado un plato que es muy apetitoso y altamente consumido por los turistas que vistan estas comunidades.

\section{Conclusiones}

Es evidente que el tema sobre el estado del hambre debe ser una prioridad en las políticas mundiales de desarrollo. La alarmante cifra de que 1 de cada 8 personas con mal nutrición es un dato que debe relacionar toda propuesta proactiva, para cambiar esta realidad global, con un proceso de acción colectiva mundial. Es además un hecho sobre el cual las políticas locales, nacionales y regionales deben aunar esfuerzos para colaborar a escala global, asumiendo el reto de los objetivos del milenio como un primer paso para reducir las grandes brechas existentes en la alimentación mundial.

El Ecuador tiene una Constitución y una Ley vanguardista en este aspecto, la misma se encuentra en un proceso de implementación y sería muy conveniente monitorear este proceso. De esta forma, con investigaciones relativas al tema, se podrá retroalimentar con valiosos conocimientos sobre los principales impactos -positivos y negativos- que genere este cuerpo legal en su aplicación en el territorio. Hay aquí una línea de investigación que bien se la podría desarrollar en base a equipos multidisciplinares.

El turismo comunitario tiene propuestas positivas para aportar a las políticas de soberanía alimentaria. Destaca su potencial relación con varios procesos y subprocesos del sistema alimentario, al mismo tiempo que es una fuerte conexión para lograr la diversificación productiva $\mathrm{y}$, más aún, para asentar temas transversales como la sanitación y nutrición. Destacan programas del Estado ecuatoriano para reforzar el manejo de alimentos y temas nutricionales, con base en campañas públicas y a cursos de capacitación (considerando las Normas INEN sobre puestos de trabajo en el turismo). Esta relación ha dado relevancia turística al proceso agroindustrial en comunidades, ya que en varios casos, como por ejemplo Salinas de Bolívar, los turistas observan y participan en algunas técnicas de producción de alimentos y bebidas como una experiencia enriquecedora de aprendizaje. En otras comunidades los turistas participan en actividades como la cosecha gastronómica, en la cual se vincula la participación de los visitantes desde su involucramiento en las labores agroproductivas del territorio, hasta la producción de alimentos y bebidas con interesantes características culturales.

Se han elaborado propuestas, en conjunto con las comunidades, sobre posibles implantaciones de empresas comunitarias turísticas con un fuerte enfoque en lo gastronómico. En todas las comunidades destaca el principio de rescate cultural de la gastronomía, como un eje transversal. Además, 
sobresalen propuestas de proyectos productivos que se han generado sobre la significación de productos e ingredientes determinados, como por ejemplo los citados casos de la naranjilla o el con-

\section{Referencias}

Allauca, J., \& Vaca, I. (2004). Miño San Antonio, una comunidad productiva y con futuro (Tesis). Universidad de Especialidades Turísticas. Ecuador.

Barragán, S. Hinojosa, E. (2006). Campo Libre. Finca de Agroturismo (Tesis). Universidad de Especialidades Turísticas. Ecuador

Cabanilla, E. (2005). Turismo Comunitario. Marca Competitiva del Ecuador. Turismo, patrimonio y desarrollo (TURPADE). Confederación Panamericana de Escuelas de Hotelería Gastronomía y Turismo.

Cabanilla, E. (2013). Manual integral de trabajo de campo, con un enfoque participativo, en lo social, espacial y económico, para la determinación potencial de la relación comunidad / turismo. Del diagnóstico al plan de negocio. Ecuador: Licencia Creative Common. Atribución-Compartir Igual 3.Unported.

Cabanilla, E. (2015). Impactos culturales del turismo comunitario en Ecuador sobre el rol del chamán y los ritos mágico-religiosos. Estudios y Perspectivas en Turismo, 24, p. $356-373$

Durán, C. Endara, R. (2011). Circuito de senderos agroturísticos Achiotillo y Cafetería (Tesis). Universidad de Especialidades Turísticas. Ecuador

FAO. (2013). El estado mundial de la agricultura y la alimentación. Roma: FAO

FAO. (2015). El estado del hambre. Recuperado de: http://www.fao.org/hunger/es/

Instituto Ecuatoriano de Normalización (2008). Norma de Puesto de Trabajo: Cocinero Polivalente. Norma NTE INEN 2 441:2008. Ecuador: INEN.

Jara, H., \& Santamaria, A. (2009). Atlas arqueológico: Distrito Metropolitano de Quito (Vol. 1). Quito: FONSAL. sumo del cuy. Inclusive se han realizado estudios que proponen la innovación culinaria basada en a productos ancestrales, tal como el citado caso del amaranto.

Llive, C. Pacheco, M. (2009). Circuito turístico de fincas comunitarias "El Naranjillado" Comunidad de San José de Saloya (Tesis). Universidad de Especialidades Turísticas. Ecuador

Ministerio de Turismo del Ecuador. (2007). Plan estratégico de desarrollo del turismo sostenible en Ecuador hacia el año 2020: PLANDETUR 2020. Quito: MINTUR.

Morales, C. Proaño, X. (2006). Implementación de procesos de mejoramiento de los servicios de la hostería El Refugio (Tesis). Universidad de Especialidades Turísticas. Ecuador

Morales, F. (2006). Turismo comunitario: una nueva alternativa de desarrollo indígena. AIBR: Revista de Antropología

Patiño, A. (2011). Feria Gastronómica Uyumbicho (Tesis). Universidad de Especialidades Turísticas. Ecuador

Quintero, D. (2012). Capacitación culinaria en manipulación, servicio, preparación, y costeo de alimentos y bebidas, para la red de turismo comunitario del pueblo Cañari Sumak Pacha del cantón Cañar. (Tesis). Universidad de Cuenca. Ecuador.

República del Ecuador. (2008). Constitución Política. Ecuador: Asamblea Nacional.

Ruiz, E. Solís, D. (2007). Turismo comunitario en Ecuador: desarrollo y sostenibilidad social. Ecuador: Editorial Abya Yala.

Tamayo, V. \& Hervas, V. (2004). La Granja (Tesis). Universidad de Especialidades Turísticas. Ecuador

World Tourism Organization WTO (2012). Global Report on Food Tourism. Madrid: UNWTO. 